\title{
Activation of p-Type GaN with Irradiation of the Second Harmonics of a Q-Switched Nd : YAG Laser
}

\author{
Yung-Chen Cheng (a), Chi-Chin Liao (a), Shih-Wei Feng (a), \\ Chin-Chung Yang ${ }^{1}$ ) (a), Yen-Sheng Lin (b), Kung-Jeng Ma (b), and \\ JEN-INN ChYI (c)
}

(a) Department of Electrical Engineering and Graduate Institute of Electro-Optical Engineering, National Taiwan University, 1, Roosevelt Road, Sec. 4, Taipei, Taiwan

(b) Department of Mechanical Engineering, Chung Cheng Institute of Technology, Tahsi, Taoyuan, Taiwan

(c) Department of Electrical Engineering, National Central University, Chung-Li, Taiwan

(Received June 23, 2001; accepted August 1, 2001)

Subject classification: 61.80.Ba; 71.55.Eq; 78.55.Cr; S7.14

\begin{abstract}
Efficient activation of $\mathrm{Mg}$ acceptors for obtaining a high hole concentration is a challenging topic. In this paper, we report the results of $\mathrm{Mg}$ acceptor activation in $\mathrm{GaN}$ with irradiation of the second-harmonic photons (532 $\mathrm{nm}$ in wavelength) of a Q-switched Nd:YAG laser. This laser was used to irradiate two Mg-doped GaN samples of different doping concentrations. With doping concentration of $1.2 \times 10^{18} \mathrm{~cm}^{-3}$, a hole concentration of $2.66 \times 10^{17} \mathrm{~cm}^{-3}$ was obtained after laserinduced activation. The average temperature of samples during laser irradiation was around $30{ }^{\circ} \mathrm{C}$. Hence, it was speculated that the irradiation process was very unlikely to be thermal annealing. PL measurements revealed that laser-induced activation could ionize not only the shallow but also the deep donors.
\end{abstract}

1. Introduction The second harmonic photons $(532 \mathrm{~nm})$ of a Q-switched $\mathrm{Nd}$ : YAG laser were used to irradiate two Mg-doped GaN samples. The MOCVD grown samples consisted of Mg-doped GaN of $1.6 \mu \mathrm{m}$ for sample A and $0.615 \mu \mathrm{m}$ for sample B after the growth of $0.2 \mu \mathrm{m}$ (sample A) and $1.6 \mu \mathrm{m}$ (sample B) nucleation layers on sapphire substrates. The growth temperature was $1020{ }^{\circ} \mathrm{C}$. The concentrations of $\mathrm{Mg}$ doping were $6.3 \times 10^{17} \mathrm{~cm}^{-3}$ (sample A) and $1.2 \times 10^{18} \mathrm{~cm}^{-3}$ (sample B). To obtain uniform laser fluence, the laser output of $1 \mathrm{~mm}$ in beam radius was first expanded into a radius size of $2 \mathrm{~cm}$ through a defocusing lens. The central portion of the enlarged laser beam, which was believed to be quite uniform in fluence, was used for laser irradiation onto samples of $5 \times 5 \mathrm{~mm}^{2}$ in dimension. After laser irradiation, metal contacts were prepared, followed by thermal annealing at $750{ }^{\circ} \mathrm{C}$ for $20 \mathrm{~s}$ in ambient nitrogen. It was confirmed that this short-period thermal annealing process could not activate the $\mathrm{GaN}$ samples.

2. Experimental Results For comparison, we also conducted thermal activation with the same sample wafers. Thermal activation experiments were conducted with thermal annealing at various temperatures for $20 \mathrm{~min}$ (for sample A) or $30 \mathrm{~min}$ (for sample B). Figure 1 shows the variations of hole concentrations for samples $\mathrm{A}$ and $\mathrm{B}$. One can see that hole concentrations of about $6 \times 10^{16}$ and $2 \times 10^{17} \mathrm{~cm}^{-3}$ for samples $\mathrm{A}$ and $\mathrm{B}$,

\footnotetext{
1) Corresponding author; Phone: 886-2-23657624; Fax: 886-2-23652637; e-mail: ccy@cc.ee.ntu.edu.tw
} 


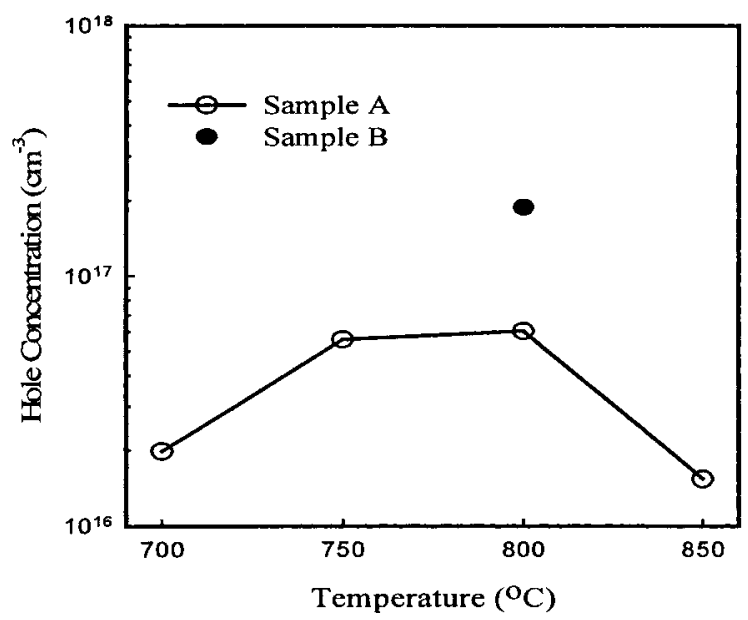

Fig. 1. Hole concentration vs. thermally activated temperature for samples A (empty circles) and B (filled circle)

respectively, were achieved with annealing at $800{ }^{\circ} \mathrm{C}$. Because of the limited size of sample B, only one data point is available. Both of them are within reasonable ranges based on previously obtained data Refs. [1-3].

The hole concentration results of laser-induced activation with various laser fluence levels are

shown in Fig. 2. Samples A and B were irradiated with 50000 and 60000 laser pulses, respectively. For sample A, the hole concentration ranges from $4.6 \times 10^{15}$ to $1.25 \times 10^{16} \mathrm{~cm}^{-3}$ when laser fluence increases from 0.094 to $0.3 \mathrm{~mJ} / \mathrm{cm}^{2}$. Also, for sample B the hole concentration ranges from $1.5 \times 10^{16}$ to $9.45 \times 10^{16} \mathrm{~cm}^{-3}$ when laser fluence increases from 0.154 to $0.46 \mathrm{~mJ} / \mathrm{cm}^{2}$. The hole concentration results of laser-induced activation with fixed laser fluence but different laser pulse numbers are shown in Fig. 3. The laser fluence levels were fixed at $0.25 \mathrm{~mJ} / \mathrm{cm}^{2}$ for sample A and at $0.23 \mathrm{~mJ} / \mathrm{cm}^{2}$ for sample B. For sample A, the case of 60000 laser pulses generated the highest hole concentration $\left(4.56 \times 10^{16} \mathrm{~cm}^{-3}\right)$, which is comparable to the level of thermally activated samples. For sample B, the case of 50000 laser pulses resulted in the highest hole concentration $\left(2.66 \times 10^{17} \mathrm{~cm}^{-3}\right)$.

3. Discussion of Activation Mechanisms As mentioned previously, the thermal process is believed to induce the dissociation of $\mathrm{Mg}-\mathrm{H}$ bonds in MOCVD-grown samples. In other words, the thermal energy ionizes shallow $\mathrm{H}$ donors and activates $\mathrm{Mg}$ acceptors. The shallow $\mathrm{H}$ donors and $\mathrm{Mg}$ acceptors correspond to the fluorescence peak near $3.2 \mathrm{eV}[4,5]$. The deep donors formed by a complex of $\mathrm{H}$ and nitrogen vacancies lead to the fluorescence peak near $2.8 \mathrm{eV}$. This PL feature has been observed in the ther-

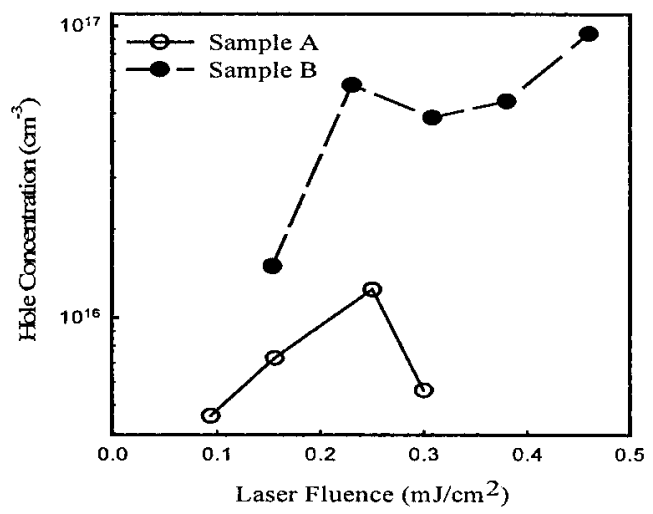
mally activated samples. To identify the mechanisms of laser-induced activation, we conducted PL measurements of sample A under different conditions, and the results are shown in Fig. 4. Here, the

Fig. 2. Hole concentration vs. laser fluence in laser-induced activation for samples A (empty circles) and B (filled circles) 


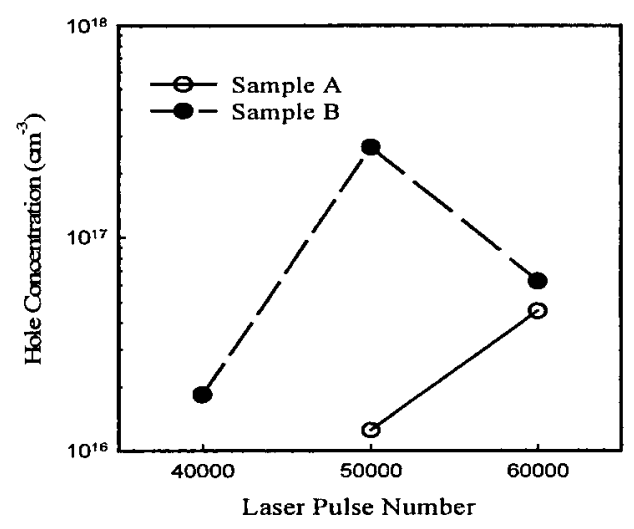

Fig. 3. Hole concentration vs. laser pulse number in laser-induced activation for samples A (empty circles) and B (filled circles)

three curves correspond to PL spectra of an as-grown sample (continuous line), a laser-activated sample (dashed line), and a thermally activated sample (dash-dotted line). The laser-activated sample was prepared under the conditions of 60000 pulses at $0.25 \mathrm{~mJ} / \mathrm{cm}^{2}$ fluence. The thermally activated sample was prepared by annealing at $800{ }^{\circ} \mathrm{C}$ for $20 \mathrm{~min}$. The hole concentra-

tion of the former is only slightly lower than that of the latter. Although the peaks around both 2.8 and $3.2 \mathrm{eV}$ are not prominent, the redshift trend of these spectra is consistent with findings previously reported [4, 5]. The as-grown sample has a peak near $3.2 \mathrm{eV}$, indicating the existence of $\mathrm{Mg}-\mathrm{H}$ complexes and their dominance over the deactivation mechanism. The PL peak of the thermally activated sample shifts to around $2.9 \mathrm{eV}$, revealing that the $\mathrm{Mg}-\mathrm{H}$ complexes have essentially been eliminated and the dominating deactivation mechanism is the effect of nitrogen vacancies. In the case of laser-induced activation, the PL spectrum lies in between. Such a spectral distribution may indicate that the used photons (with an energy of $2.33 \mathrm{eV}$ ) may partially ionize not only the shallow but also the deep donors.

To understand whether the laser-induced process was thermal, we measured the temperature of the sample during laser irradiation. The measured temperature was around $30{ }^{\circ} \mathrm{C}$, only a few degrees above room temperature. This temperature was an average value calculated from repeated pulse irradiation. A question may be raised about the possibility that high temperatures existed for a short duration (in the microsecond range) after the irradiation of one pulse. If this is true, the continuous high temperature duration would add up to with at most several seconds in the case of 40000 pulses laser irradiation (assuming $100 \mu$ s duration high temperature for one laser pulse irradiation). Even if the transient temperature was as high as $800{ }^{\circ} \mathrm{C}$, there was no evidence of thermal activation for such a short time period. It should be noted that the laser photon energy

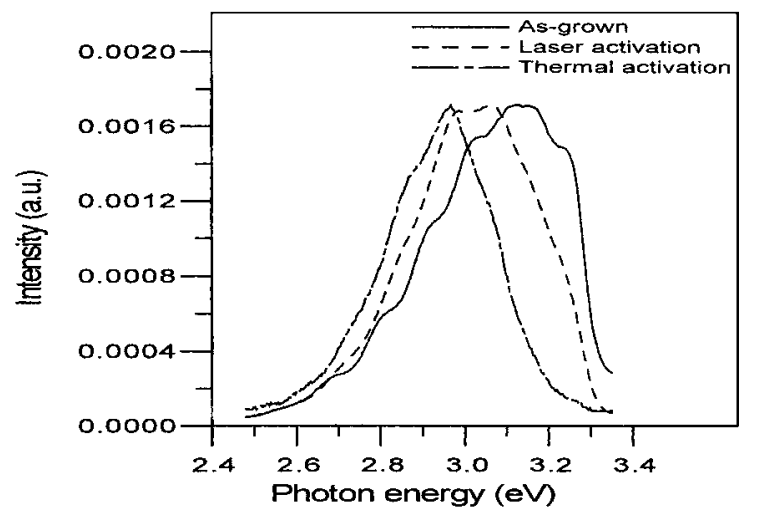
expended was $2.33 \mathrm{eV}$, which is lower than the absorption band of the samples, except possibly that caused by defects. Also, it is almost impossible for such photons to in-

Fig. 4. PL spectra of an as-grown sample (continuous line), a laser-activated sample (dashed line), and a thermally activated sample (dash-dotted line) 
duce efficient phonon generation. Hence, the process involved in laser-induced activation is very unlikely to be thermal. Note that the required energy for ionizing the shallow donors, i.e., breaking the $\mathrm{Mg}-\mathrm{H}$ bonds, is only around $1.5 \mathrm{eV}$ [6]. Increasing this value by $0.4 \mathrm{eV}$, the incident photons can possibly ionize the deep donors. Therefore, it is reasonable to speculate that photon-induced ionization of shallow and possibly deep donors is the mechanism of the laser-induced activation process. In other words, the relevant bonds are directly broken by the incident photons. However, such speculation requires further investigation.

4. Conclusions In summary, we have successfully activated $\mathrm{Mg}$ acceptors in p-type GaN samples with laser irradiation at a photon energy lower than the major absorption band. With appropriate laser fluence levels and exposure periods, the hole concentration reached the level obtained with thermal activation. Temperature measurements indicated that the laser-induced process was non-thermal. The physical mechanism of this process should be a topic for further investigation.

Acknowledgement This research was sponsored by Chung Shan Institute of Science and Technology, Taiwan, R.O.C.

\section{References}

[1] S. Nakamura, N. Inasa, M. Senoh, and T. Mukai, Jpn. J. Appl. Phys. 31, 1258 (1992).

[2] S. Nakamura, T. Mukai, M. Senoh, and N. Iwasa, Jpn. J. Appl. Phys. 31, L139 (1992).

[3] S. NaKamuRa and G. Fasol, The Blue Laser Diode, Springer-Verlag, Berlin 1997.

[4] U. Kaufmann, M. Kunzer, M. Maier, H. Obloh, A. Ramakrishnan, B. Santic, and P. Schlott, Appl. Phys. Lett. 72, 1326 (1998).

[5] F. ShahediPour and B. W. Wessels, Appl. Phys. Lett. 76, 3011 (2000).

[6] J. Neugebauer and C. G. Van De Walle, Phys. Rev. Lett. 75, 4452 (1995). 